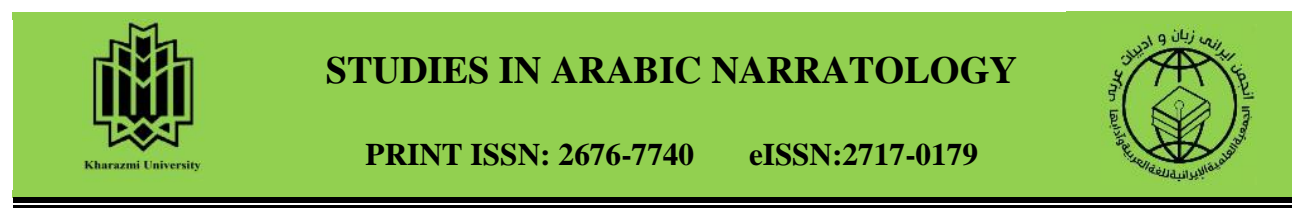

\title{
A Study of Narrative Stylistics and Violence in Contemporary Iraqi Novels: The Case Study of Khan al-Shabandar
}

Karima Nomas Muhammad Al-Madani kareema.n@uokerbala.edu.iq Assistant professor of Arabic language and literature, University of Karbala, Iraq.

\begin{abstract}
The importance of this research is the study of the quality of stylistic features in Iraqi narrative texts. This research examines stylistic and narrative features of Khan alShabandar novel. The art of fiction has a close relationship with sociocultural contexts of Arab countries, especially Iraq which has experienced destruction, lack of security and stability, division, sectarianism, exile and murder which are the products of wars. Issues of war and massacre constitute the main bulk of the oeuvre of contemporary Iraqi novelists, issues which have left significant effect on psyche of authors who combine the pain of war with the blood of the innocent people. As a result, they have begun to write down the sufferings of the country. Their fiction is the result of a true imitation of the truth with all its pains and sufferings and the ugliness of murder and terror. In fact, the creative writing of contemporary Iraqi authors shows the awareness of the danger of violence in all its dimensions. In Khan al-Shabandar novel, numerous scenes of violence reflect a bitter reality, a bitter reality which portrays bloody scenes of street explosions, destroyed buildings, the spread of fear, terror, repression, and explosions - as if the country has become a scene of war. This research seeks to examine the rhythm of events and time in the selected novel, paying attention to words of violence. It also tries to examine the context of the narrative. It might be suggested that the novel teems with rhetorical questions and command. The events, which narrate a fearful experience of a real context, are narrated based on the poetics of a rhetorical (dramatic) question.
\end{abstract}

Keywords: Arabic Narratology, fictional narration, violence, narrative, style narration.

Citation: Al-Madani, K. Spring \& Summer (2020). A Study of Narrative Stylistics and Violence in Contemporary Iraqi Novels: The Case Study of Khan al-Shabandar. Studies in Arabic Narratology, 1(2), 301-318. (In Arabic)

Studies in Arabic Narratology, Spring \& Summer (2020), Vol. 1, No.2, pp. 301-318. Received: July 25, 2020; $\quad$ Accepted: September 21, 2020

CFaculty of Literature \& Humanities, University of Kharazmi and Iranian Association of Arabic Language \& Literature. 


\section{دراسة أسلوبية لعناصر السرد والعنف في الرواية العراقية}

\section{المعاصرة؛ رواية خان الشابندر لمحمد حياوي اختيارا}

kareema.n@uokerbala.edu.iq

$$
\text { كريمة نوماس محمد المدنيي }
$$

الإحالة: المدني، كريمة نوماس محمّد. ربيع وصيف (•r.r). دراسة أسلوبية لعناصر السرد والعنف في الرواية العراقية المعاصرة؛ رواية خان الشابندر لمحمد حياوي اختيارا. دراسات في

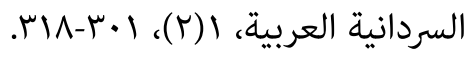

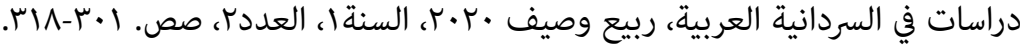

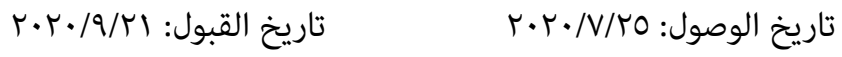

ه كلية الآداب والعلوم الإنسانية بجامعة الخوارزمي والجمعية العلمية الإيرانية للغة العربية وآدابها.

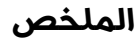

تكمن أهمية هذا البحث في السؤال عن كيفية دراسة الخصائص الأسلوبية في النص السردي الروائي العراقي. وستجيب عليها فقرات البحث في مفاصله المتنوعة ومجالات التطبيق من نصوص رواية خان الشابندر. مل يكن الفن الروائي بمنأى عما يمر به حال البلاد العربية، ولاسيما البلد العراقي من حالات الضياع وفقدان الأمن والاستقرار والتفرقة والطائفية والتهجير والقتل وهذا ما صنعته الحروب، وقد شغل الأخير مساحة واسعة من نفوس المبدعين العراقيين الروائيين الشرفاء بل ترك أثرا في نفوسهم ليمتزج ذلك الأم مع دم الأبرياء وحبر أقلامهم فانبروا يكتبون كل ما مر به هذا البلد من آهات 
وويلات فكانت أعمالهم الروائية محاكاة حقيقية للواقع بكل آلامه ومرارته وبشاعة القتل والرعب. فإن النص الإبداعي العراقي المعاصر وعى خطورة العنف بكل مدياته. وفي رواية خان الشابندر نجد مشاهد العنف متمثلة بواقع مرير يتجسد بمشاهد دامية من انفجارات الشوارع والبنايات المهدمة وانتشار الخوف والرعب والأشباح، والإضرار

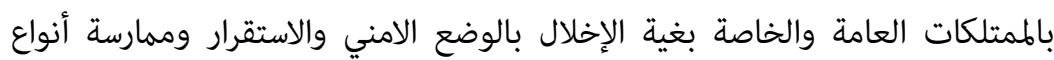
القمع والقتل والتهجير وتصاعد إطلاقات النار والانفجارات المتتالية وكأن البلد أصبح ساحة حرب. وقد ارتأت الدراسة أن تكون على مدخل للتعريف بففهوم العنف في اللغة والاصطلاح ثم دراسة إيقاع الأحداث والزمان في الرواية المذكورة، ثم تحاول الدراسة النسقية للصورة التركيية للرواية التي تمثلت بنسقي الاستفهام والأمر و نسقي

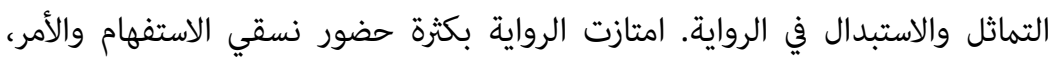

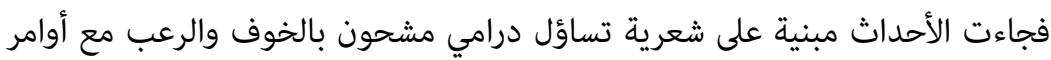

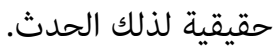

الكلمات المفتاحية: السردانية العربية، السرد الروائي العراقي، مشاهد العنف، الرواية العراقية المعاصرة، أسلوبية السرد الروائي. 
الحمد لله رب العالمين، والصلاة والسلام على خير خلق الله أجمعين ابي القاسم محمد المصطفى الأمين وعلى آله الميامين الى قيام يوم الدين. وبعد..

يعد العنف موضوعا معقدا، تتشابك فيه مجموعة من العلوم كعلم النفس، علم الإجتماع، وعلم

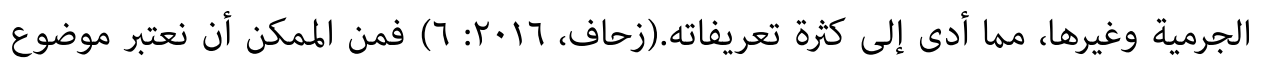
العنف من ضمن بحوث متعددة التخصصات التي يحاول انعكاس مختلف وجوه المجتمع ومشاكله الإجرامية والاجتماعية والنفسية نتيجة لظروف المجتمع والأشخاص وعاداتهم المعيشية. إن روايات حرب العراق مسكونة بتصوير الأذى المعنوي والتعبير عن الذنب الذي لم يتم حله. بعض من هذه الروايات تدل على حالات الإجرام و حالة الحرب العراقية يكن تفسيرها جزئيًا من خلال صعود العالمية الأخلاقية وعدم وضوحها من الخطوط المفاهيمية التقليدية بين الحرب والجريمة( (2020: iii Brazeal ملحكية إن مفهوم العنف في المعاجم اللغوية هو الخرق في الأمور، واعتنف الأمر إذا أخذه بعنف وشدة.(ابن منظور،جا، ...r: باع). أما ما ورد عن مفهوم العنف اصطلاحاً يشير إلى أنه إنه خطاب أو فعل مؤذ أو مدمر يقوم به فرد او جماعة ضد أخرى، والعنف انتهاك للشخصية بمعنى انه تعد على الآخر وإنكار له أو تجاهله، وأي سلوك شخصي أو مؤسساتي يتم بطابع تدمير فورد

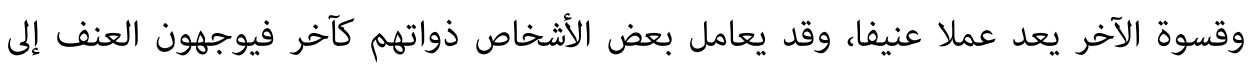

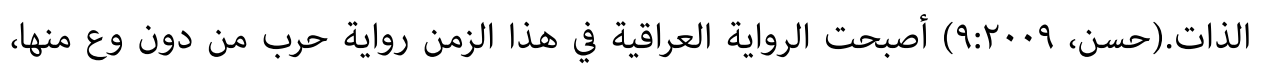

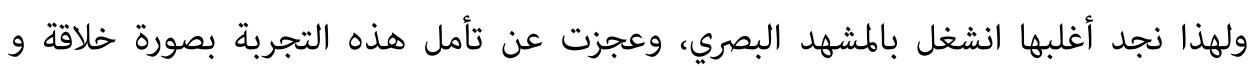
وقعت في المشكلة نفسها التي وقعت فيها الرواية العراقية زمن حروب الدكتاتورية مع الفارق. يرجع بعض الباحثين إلى أن أدب الحرب العراقي السابق هو أدب لا يعتد به؛ لأن تلك الحورب

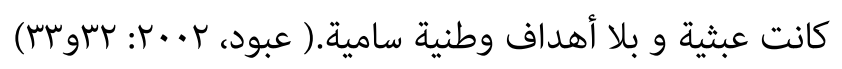
فالأحداث السياسية التي عصفت ببلد العراق سببت الأزمات والفتن الطائفية وفقدان الأمن والقتل والرعب والعنف، وكل هذه المشاهد مل تكن بعيدة عن أنظار الروائيين العراقيين، لذلك 
وجدت الرواية العراقية نفسها أمام واقع مرير ومستقبل مجهول، فكانت رواية خان الشابندر شاهدا واقعيا لتصوير مشاهد العنف والدمار الذي حل ببلدنا وما تعرض له العراقيون الأبرياء. أسئلة البحث يحاول هذا البحث الإجابة عن الأسئلة التالية: ا. كيف تجسدت مشاهد العنف في رواية خان الشابندر؟ r. ما هي مميزات الأسلوب و الزمن والإقاع في الرواية المذكورة؟ خلفية البحث فيما يتعلق بالدراسات السابقة لهذا البحث، فيمكننا القول أننا وجدنا بعض المصادر التي تناولت هذه الدراسة و حللتها من بعض الوجوه. منها:

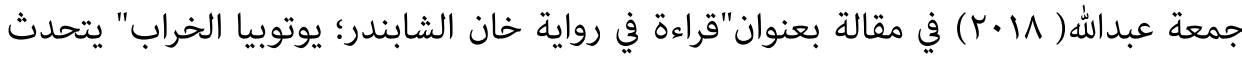
عن تراجيدية الخراب و الدمار في هذه الرواية مشيرا إلى أهم شخوص الرواية مثل هند و

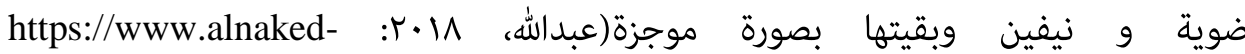
.(aliraqi.net/article/52460.php ثم كه يلان محمد(Y IV) في مقالة على الشبكة العنكبوتية تحت عنوان" نقد خان الشابندر لمحمد حياوي... والنبش في عام المهمشين"، أشار إلى بعض تمظهرات العجائبية في بناء بعض

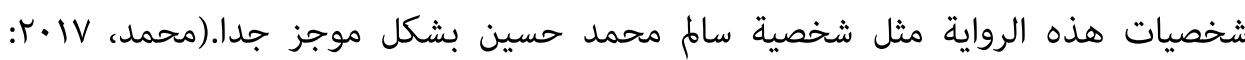
https://www.alraimedia.com/Home/Details?id=7f6f0851-d57b-4611-8024(5d87e267e9a1 قصص متوالدة للمُهمّشين والأموات"فنجد أن الباحث أشار إلى بعض ملامح الراوي في هذه هـه الرواية و استخدام الشخصيات الهامشية فيها مختصرا كما أشار إلى استخدام السرد الخيالي واللغة الشعرية فيها من ضمن مميزاتها الخاصة. ثم عبدالغني بومعزه(10 · ( ف) في مقالة بعنوان "رواية خان الشابندر.. الفجيعة والإنسحاق المجتمعي"، تناول آثار يوتوبيا لمدينة بغداد المنتهكة و الخانات المهجورة وانتشار الخوف وإراقة الدماء في الرواية المذكورة مختصرا. (https://www.nawafedh.org/node/588) 
والرسائل الجامعية، فلم نجد بحثا تناول أسلوبية السرد في رواية خان الشابندر متزامنا مع دراسة إنعكاس العنف فيها و دراسة إيقاع الزمن والأحداث و أثرهما على هذه الرواية.

\section{هدف البحث}

يهدف هذا البحث إلى دراسة أسلوب السرد ومشاهد العنف في الرواية العراقية الطعاصرة مركزا على تحليل بعض عناصر رواية خان الشابندر الروائية السردية.

منهج البحث

نعتمد في هذا البحث على المنهج الوصفي التحليلي حيث نحاول التعرف على ظاهرة العنف و التعرف على مميزات الأسلوب الروائي في رواية "خان الشابندر". إذن نسعى إلى تحليل الظواهر الأسلوبية و المضمونية للعنف في هذه الرواية.

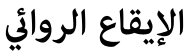

إن الأدبية التي يمنحها الإيقاع للخطاب الأدبي تتجلى في مظاهر إيقاعية متنوعة وهو يعد مظهرا للتآلف والانسجام ويتمثل في كل مظاهر الحياة وليست مشكلة الإيقاع مقصورة على الأدب بشكل نوعي أو حتى اللغة فهناك إيقاع للطبيعة وللعمل ولكل شيئ(مصطفى، 10 •r: مب)ولا يقتصر الإيقاع في الأدب على الشعر بل يكون في النثر أيضا، فالإيقاع جزء أساس من التعبير النثري والسردي أيضا، إذ يحقق غرضيين أساسيين هما تأكيد المعنى وإبراز العواطف بشكل واضح(بلا مؤلف، 191ا،ب(1)ويحقق الايقاع في الرواية اللذة والمتعة المبنية على الأحداث والمشاهد المتناسقة والمنسجمة مع بعضها في العمل الروائي ـ ومن أهم هذه الظواهر الإيقاعية.

\section{إيقاع الأحداث}

يبنى الايقاع الروائي على مايسرد من أحداث في نسق ينسجم مع بناء الرواية الكلي، وتعود أهمية هذا النوع من الايقاع في الرواية الى فاعلية الحدث بصفته عنصرا مؤثرا في إضفاء الحركة على بنية النص الروائي، فلذلك عرف الحدث بأنه ״كل مايؤدي الى تغيير أمر او خلق حركة او انتاج شيء، ويكن تحديد الحدث في الرواية بأنه لعبة قوى متواجهة او متحالفة تشكل بدورها حالات محالفة او مواجهة بين شخصيات)(مصطفى،10 •r: 9ץ). ولعل مانجده في رواية خان 
الشابندر إيقاع أحداثي متميز بين تراتب إيقاع الأحداث من الهبوط إلى الصعود بالتناسق مع الأحداث إذ يقول بطل الرواية (علي الصحفي) وهو يتجول في شوارع بغداد القديمة (اجتزأنا أول بئل مرة أزقة ضيقة تملأها الأزبال وأنقاض البيوت المهدمة ...ثم سرعان ما صرنا نخترق خرائب آيلة للسقوط وبقايا بيوت بغدادية قديمة هدها الزمان فاتكأت على بعضها بعضا في مشهد مرعب، وبين الفينة والأخرى يطالعنا رجل ما أو امرأة تحمل قدرا ... يخرجون فجأة من الزوايا المظلمة ويدخلون في فتحات او أبواب غير مرئية ..كما لوكانوا اشباحا تزايدت مخاوفي من تلك الأمكنة .لكن صاحبي أبدى دراية ومعرفة متناهية، الأمر الذي بعث بعض الطهأنينة داخلي،).(حياوي، مريكا.

$(9: r \cdot 10$

لو تفحصنا هذا التماوج الايقاعي الذي وظفه الكاتب في توظيف الأحداث ذات النغمات الموسيقية المتنوعة عبر تلك الإيقاعات الباعثة على الخوف والرعب ثم تبلغ قمتها لتصل الذروة وبعدها يهبط الإيقاع حين نظر إلى ملامح صديقه لمعرفته بالككان فشعر بالاطمئنان. ومن المشاهد الأخرى التي تتمتع بإيقاع حدثي متفاوت خروج علي الصحفي من بيت أم صبيح في منتصف الليل وسط تلك الظروف والاحداث القلقة غير الآمنة التي عاشها العراق في ظل سقوط النظام البائد وسيطرة قوات الاحتلال ״كان الظلام قد أطبق او كاد، وصار المشي في الأزقة الضيقة والمتداخلة مخاطرة كبيرة ...ومما زاد من قلقي إيغال صاحبي في الشرب، لكنه كمن يعرف طريقه، مررنا بعدد من الخرائب الموحشة ...كان الوضع مفزعا بحق ...لكني كنت فرحا بالحصيلة التي خرجت بها من تلك المغامرة العجيبة ...ثم فارقني صديقي باتجاه باب المعظم، كان الوقت متاخرا للحصول على سيارة أجرة تقلني إلى الكرادة والليل في بغداد مخيف مثل هذه الساعة . مررت على نقطة تفتيش كان جنودها يشعلون نارا في برميل صغير .صاح احدهم

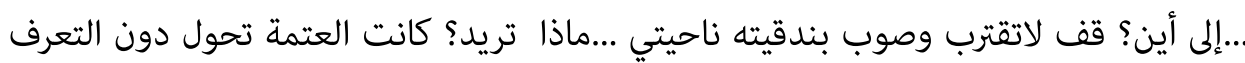
على ملامحه كان ملثما ومستفزا..ابحث عن سيارة؟ أجرة تقلني إلى الكرادة. وهذا ما نجده في كلامه حين (اقطت قذيفة هاون في المقبرة، فارتفع عمود من التراب والحجارة التي تساقطت مثل المطر فوق رؤوسنا، وحلَّقت الفواخت جافلة تضرب بأجنحتها الكبيرة، ولمت زينب من بعيد تغسل قبر امها بالماء الملون الذي ابتعته لها، بينما بدأ أخوتها 
الصغار يلهون بلعبهم الصغيرة غير عابثين بالتراب الذي غطى كل شيء)(المصدر نفسه: 17 ) مما منح النص قيمة اسلوبية عملت على التكثيف السمعي لجوانب الإيقاع والإيحاء والدلالة. ومن أمثلة إيقاع الحدث أيضا ما رواه الروائي حين التقى بطل الرواية بصديقه سام فناداه (سالم

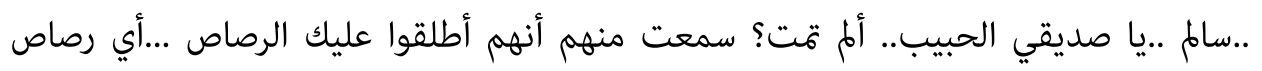

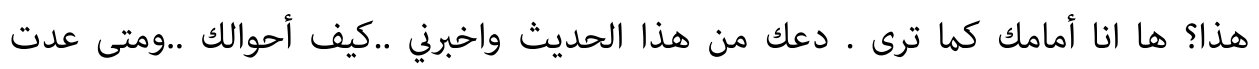
للعراق؟ ومالذي تفعله هنا في مثل هذا الساعة المتأخرة؟) (المصدر نفسه: عع) هنا الروائي يعتمد على خط الزمن المسبق الذي رافق احداث الرواية اي إيقاع الحدث في الرواية في ذاكرة

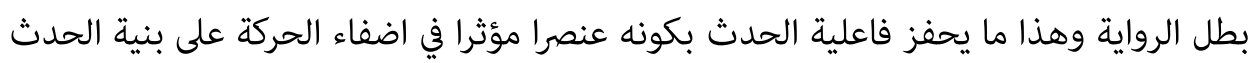
الروائي.

ثالثا: إيقاع الزمان يشكل الإيقاع الزمني عاملا مهما وفاعلا في أحداث السرد الروائي، وهو يرصد الظروف النفسية والاجتماعية التي يمر بها شخوص الرواية، ولعل الزمن النفسي هو زمن الشخصية الروائية الذي الذي يخضع للانفعالات والحالات النفسية والشعورية ويشكل ركيزة أساسية من ركائز الإبداع ففيه دلالات إيحائية وشعورية وإشارات جمالية معبرة عن الفكر والمشاعر والرؤى.(حسن،ع..r:

ومن أمثلة ذلك في رواية خان الشابندر حين تحدث مع صديقته في العمل المرأة المسيحية (نيفين) التي كانت تحرص عليه كثيرا وتفتقده دائما إذ يقول لها (تسعة انفجارات حتى الان ...ومازلنا بمنتصف الطريق سيحرقون بغداد من الان حتى المساء «(حياوي، 10 • ب: • 9) نلاحظ في هذا النص ظاهرة الزمن وهي من الظواهر الأسلوبية، التي تسهم في عملية الإيحاء، أئاء وتعميق أثر الصورة في ذهن القارئ، ومن أمثلة الزمن الروائي أيضا حين التقى بالشابة (زينب التي عمرها لايتجاوز الرابعة عشر وهي تبيع الكعك لتعيش مع أخوتها، فهي المعيلة بهم فعندما

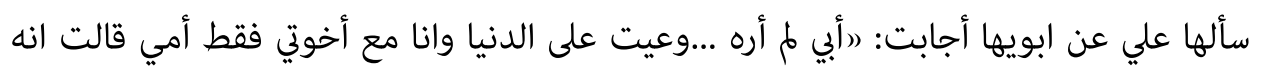
قتل في رصاصة الانتفاضة ...وفي العام الماضي مرضت أمي وماتت الحاج زيدان مل يحضر لها الدواء دفنوها بمقبرة الشيخ معروف ..في العيد الماضي أخذت أخوتي وزرناها ..هي أوصتني قالت 
لي قبل أن تموت :ماما زينب انتبهي لأخوتك ولا تتركيهم، لكن لا استطيع الذهاب إليها باستمرار .لان اليوم الذي لا أشتغل فيه يموت أخوتي من الجوع). (المصدر نفسه: • 7) المستوى التركيبي

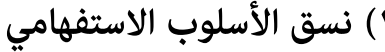

من الظواهر الأسلوبية المتميزة في رواية خان الشابندر هو نسق الاستفهام إذ يعد أحد

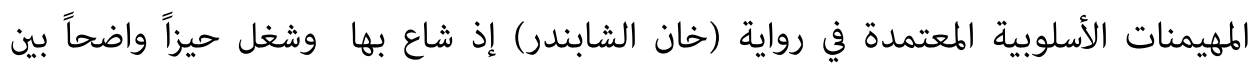
الأساليب الأخرى ويستمد الخطاب الاستفهامي من معين الخطاب الإخباري لاحتضان الخطاب الإخباري مضامين زمانية أو مكانية او سببية فيكون جملة حاضنة للشيء الذي تستعمل فيه هذه الأدوات في السؤال عنه فيبحث التركيب الاستفهامي عن كشفها واستظهارها بتقنيته الخاصة ـ إن أسلوب الاستفهام في هذه الرواية في أغلبه يتحول من معناه من جملة استفهامية حقيقية إلى جملة أخرى تعجبية او منفية او إخبارية كما نجد في هذا النص. فمن أمثلة ذلك نجد أسلوب الرواي، لأنه الوسيط بين مؤلف الرواية وقارئها فهو (الواسطة بين العالم الممثل والقارئ وبين القارئ والمؤلف الواقعي فهو العون السردي الذي يعهد إليه المؤلف الواقعي بسرد الحكاية اساسا ويهتدى اليه بالاجابة عن السؤال من المتكلم ) (محمد،Vا •r: (•) حين يحكي لصديقته نيفين عن لقائه بصديق قديم مات منذ زمن، إذ أعدمه النظام البائد بالرصاص فتعجبت نيفين من كلامه: ״ هل تتحدث بجد؟... ما بك؟ .. هل جننت؟ .. ساملم مات منذ أكثر من خمس وعشرين سنة... ألم يعدموه بالرصاص وقتها؟)، (حياوي، 10 • ب: 010). أن أسماء الاستفهام في هذه الجمل لم تؤدّ الوظيفة المطلوبة التي وضعت من اجلها، بل نجد قد انحرفت عن معناها الأصلي في الاستفهام، لأنها لا يراد بها الاستفهام، وانما اسئلة يراد بها التعجب. لذلك نجد ان السياق الاستفهامي قد كشف غرض الكاتب وأن الشخص مازال حيا وما يمت، وأن هذه الإجابة يجب على المتلقي اكتشافها وان كانت ضمنية. كذلك نجد الروائي في روايته (خان الشابندر) قد كرر الاستفهام ب(هل) اكثر ادوات الاستفهام حضورا، وهناك أحداث 
كثيرة في الرواية مبنية على بنية التساؤل التي تدور حول حكايات العنف التي عانها افراد

$$
\text { الشعب العراقي. }
$$

فمن أمثلة ذلك يروي لنا بطل الرواية لقائه مع هند إحدى فتيات أم صبيح ... تروي قصتها له وكيفية موت زوجها عند نقل ابنتهم سارة من مدينة الناصرية الى بغداد في أحداث إناث 1991 تقول "اوفي الطريق من الناصرية الى بغداد أوقفتنا نقطة تفتيش قرب مدينة الكوت واعتقدنا انها الثوار ..لكن تبين لاحقا انها رجال الحرس الجمهوري فأنزلونا جميعا من السيارات الآتية من الجنوب وجمعونا في ساقية قديمة للبزل كان هناك أكثر من مائتين من الرجال والنساء والأطفال وكان الليل حالكا وفجأة أخذوا يطلقون النار علينا فتعالى الصراخ وصيحات الفزع فدفعني زوجي بأتجاه الساقية ورمى بجسده فوقنا وانحشرت سارة بيننا الى أن صار الفجر تنبهت لحركة قريبة مني ...bحت احد الرجال يقترب بعد ان لفتت انتباهه بكاء سارة ثم سألني هل هناك بـاك ناجون غيركم؟؟ فأجبته مرتبكة ...لا أدري لقد أطلقوا النار علينا “( المصدر نفسه: عسبا-سبرا) ومن أمثلة ذلك ايضا قول بطل الرواية حين سأل صديقه: "هل تراهم؟ من؟...الملائكة؟ ..طبعا أراهم ...انظر حولك ..نظرت حولي مندهشا مرتهبا، وم أر سوى الظلام المطبق على سطوح الخرائب الههدمة ... في الواقع، طاما سمعت حركة ما أو خفق اجنحة ما، وشممت رائحة زكية تنبعث من الزوايا لكنني مل ار شيئا ...لقد أرعبتني ياعم مجر...)

لقد شكل أسلوب الأمر سمة اسلوبية بارزة في رواية خان الشابندر وافا جاء الكاتب بهذا الاسلوب ليكشف عن طبيعة الشخصيات وسلوكها ومستواها الثقافي، إذ أن طبيعة هذه الرواية قد اقتضت بصدور أوامر من جهة عليا وقد نجح الكاتب في التجانس مع المواقف والاحداث . وقد عرف الامر قديماً وحديثا بتعريفات عدة: فالأمر هو : طلب الفعل على وجه الاستعلاء والالزام ولعل التعريف الجامع للأمر قولنا بإنه :

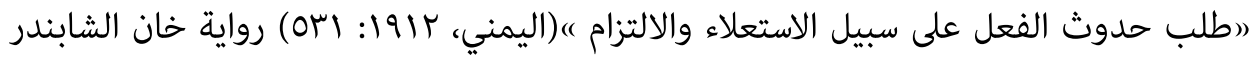


"(سأنتظرك خارج المطعم حتى تنتهي من غذائك. لا.. ضعي الصينية جانباً واذهبي لتغسلي يديك. نظر إليّ باندهاش وحيرة .. ثم مسحت المطعم بنظرة مسترقة. ما بك. يا زينب؟ قلت

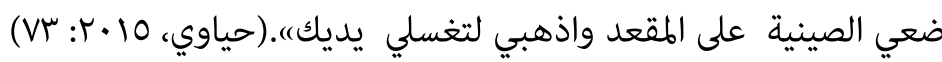
لقد شكل فعل الامر دلالة قوية معبرة عن فكرة النص في حمل المتلقي المسؤولية والطاعة لتلك الاوامر برغم من ان الكاتب قد جاء بها بصيغتها الصريحة. ومثل ذلك ما نجده في هذه

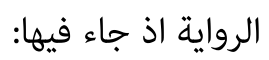
" لا تدعهم يحكّموه .. أعطه مداه. لا تشح عليه. إنّه شغفك وانت أعلم به.. فاجلس وتنفس إنس

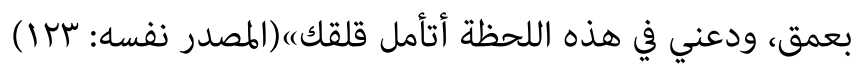
نرى في هذا النص تكثيفاً واضحاً في استعمال افعال الامر الدالة على استنهاضه متوخياً منه الحذر واليقظ وقد استطاع الكاتب ان يمنحها صفة الاستمرارية المستقبلية. وقد يكون الامر موجها (للتنبيه والحذر) كما جاء في هذا النص : " مسناً يا جدتي .. انتبهي لصحتك واهتمي بالأولاد .. قد لا أستطيع المجيء ثانية وإذا حدث شيء، إبعثي أحد الأولاد إلى مجر وهو يتصرف.. الحمى ...أية حمى؟؟هل سأموت؟؟ لا...لا

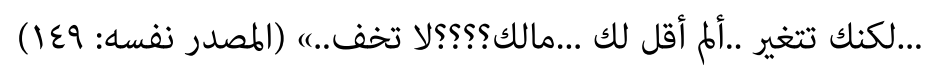
ومن أمثلة ذلك أيضا حديث هند مع الصحفي علي الذي تعلق قلبه بها عند زيارته لبيت أم صبيح اذ تقول هند حين التفت صوب الخزانة ثم عادت فاحتضنت علي بقوة _اهدأ ياحبيبي ـ

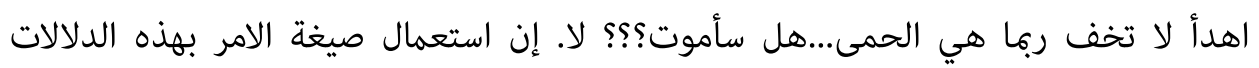
والإيحاءات جعلت المتلقي انساً منفعلاً وهذا الانفعال الوجداني لعب دور التأثير في المتكلم.

r. (المستوى التصويري

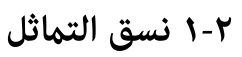
تتحقق علاقات المشابهة في اطار عنصري التشبيه والاستعارة اللذين يقومان على أساس المشابهة في المستوى الدلالي عبر خلق علاقات حيوية جديدة تبتعد عن الجانب العقلي وتقترب من

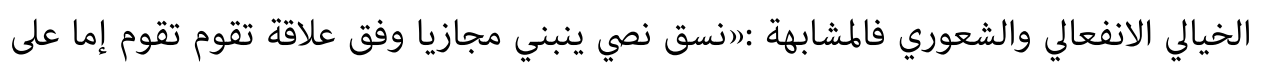

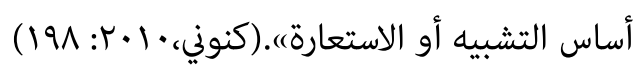


"التشبيه وسيلة أسلوبية يستعملها الأديب لتقوية المعنى وتعميق الدلالة وهي جزء من تكوين التجربة الشعورية، بل هي ملمح من ملامح العمل الأدبي الفني،(الداية،•إ199: ع9)وقد

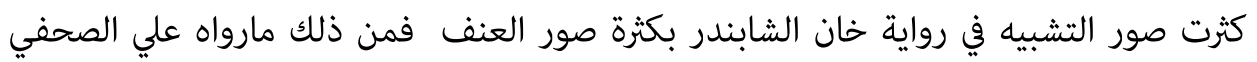
لصديقته(نيفين)ماحل ببيت أم صبيح والفتيات هند وضويةوأخلاص يروي لها (ركان صوت مجر يختفي ويعود بأذني ولم اعد واثقا انه صوته هو ..وخيل لي انني أسمع أصوات الفتيات تنبثق من الجدران تخالطها ضحكات متقطعة ..حتى أنني اكاد اميز بينها صوت هند بنبرته العذبة وهالني منظر الناس وهم يسيرون بأتجاه النهر غير عابئين بالقنابل والرصاص كانوا ينسابون بنعومة وصمت ولا تكاد أقدامهم تلامس الارض ...وصرت أطلق صوتا يشبه العواء المكتوم ونيفين تحتضنني وتهدىء من روعي)(حياوي، 10•r: IVI)، إذ ظهرت تشكلات الصورة

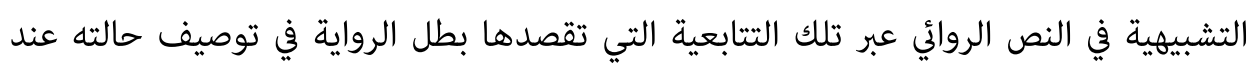

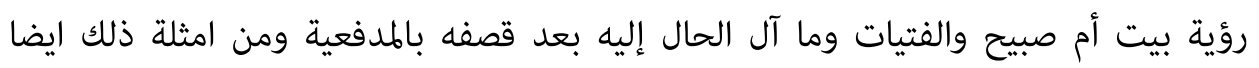
يحدثنا بطل الرواية علي يقول (ركنت حائرا وساقاي لا تحملاني .وقلبي يخفق بشدة مثل حمامة محبوسة وسط أضلاعي المضطرمة وشعرت بتيار غامض يسري بجسدي كله عبر يد نيفين الصغيرة القابضة على يدي برحمة)،(المصدر نفسه: IVT). وهنا تقوم الصورة التشبيهية على بلورة الحالة النفسية والشعورية التي يمر بها الصحفي علي بوصفها محركا فاعلا للتصوير وهو وصف حالته كالحمامة المحبوسة فهذا النوع من التشبيه فيه وصف دقيق يجسد حقيقة شعوره اتجاه ما رأت عينيه ترتقي الصورة التشبيهية الى مستوى التخييل.

\section{r-r نسق الاستبدال}

تعرف الإستعارة بأنها: (استعمال اللفظ في غير ما وضع له لعلاقة المشابهة بين المعنى المنقول

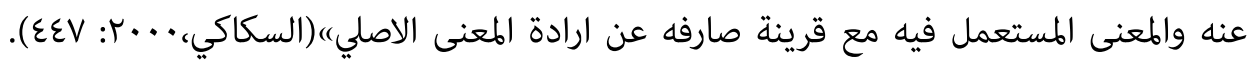
فالإستعارة تقتضي وجود علاقة مشابهة بين المستعار له و والطستعار منه، أساسها اشتراكهما بصفة معينة او جملة من الصفات فهي تثبت المعنى للمستعار له وتكون بطريقتين: ومن أمثلة الاستعارة نجد في هذا النص: (ما الذي يجري لنا؟... مَ الزمن طاغ إلى هذا الحد؟ الزمن يكون أكثر لهرئ 
وطأة وعدوانية في الحروب يا صديقي يمرّ على البشر والشجر والحجارة و فيترك آثار أظافره

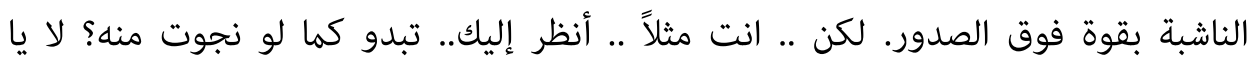
صديقي .. لقد مزقني من الداخل وعرّشت أشواكه وسط أضلاعي، وان بدوت معافى من

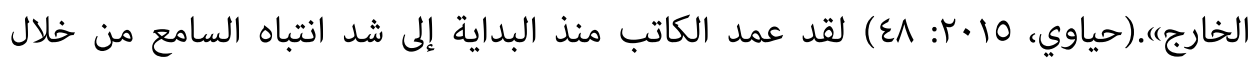
تجسيد الاستعارة حيث جعل من (الزمن) على هيئة جيش كبير قاسي عدواني خصوصاً في الحروب وعندما يمر لا يترك اي شيء أمامه سوى الآثار دليل على قسوته، وقد جسدت(الاستعارة المكنية) التي استعارها لآلامه وفرقه وحزنه بتجسيد عدوه بأظافره الناشبة ومزقته من الداخل وعرّشت من الداخل أشواكه ومزقت اضلاعه. والجدير بالذكر ان للاستعارة موقعا بارزا في رواية خان الشابندر اذ نجد منها: (القد خبرنا الموت يا أستاذ علي.. أنا شخصياً استشهدتُ في القادسية

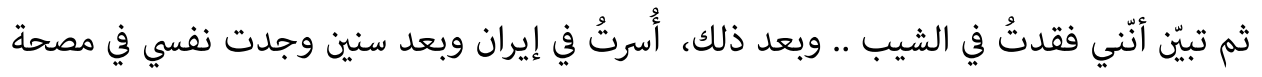
عقلية .. هذه السيارة الثانية التي اقتنيتها بعد أن احترقت الأولى في انفجار الصدرية وبعد سنين وجدت نفسي في مصحة عقلية ...هذه السيارة الثانية التي اقتنيتها بعد ان احترقت الأولى في انفجار الصدرية خرجت منها محترقا، وتعجب الناس كيف نجوت من الحادث أنا ميت يا أستاذ من زمان ...فهل يخاف الميت من الموت)(المصدر نفسه: •9) وقد شخص الروائي في هذا النص الموت إنساناً ويخبره ماذا يجري في الموت متكئاً على الاستعارة المكنية مكملاً صورته الإستعارية بصورة أخرى رسمت معالمها في صورة الموت فجاء بصورة (استشهدت في القادسية) دلالة على ان الموت قد حصل وعبر عنه بالاستعارة المكنية فاسقط بعض الأفعال الإنسانية ليسهل تقبلها ويقربها للمتلقي عندما يقول: بعد سنين وجدت نفسي في مصحة عقلية، فالتشخيص هنا الوسيلة التي قكن المبدع من تصوير المشاهد المرعبة التي مر بها بطل الرواية من اقسى حالات العنف والموت.

النتيجة

إن النص الابداعي العراقي الروائي تصدى لظاهرة العنف والإرهاب،فكانت النصوص الروائية العراقية ممثلة لموضوع الإرهاب بكل مشاهد العنف الدموي والقتل. ثم عكست رواية خان الشابندر للروائي محمد حياوي مشاهد العنف الارهابي بكل عنجهيته ووحشيته في القتل 
والتهجير والقتل. مثلت الشخصيات الروائية انعكاسا حقيقيا لكل افراد الشعب العراقي وماعاناه من آهات وحروب وتعسف بدءا من الحرب العراقية الايرانية وحرب الكويت وإمريكا التي راح ضحيتها الآلاف والملايين من أبناء هذا الشعب المظلوم على مختلف مكوناته نتيجة لقرارات حكام و مسؤولي العراق المستبدين سابقا. مثلت إيقاعية الأحداث والزمان محورا فاعلا في كشف مشفي نسقية النص الروائي فارتبطت سير الأحداث وايقاعها بأحوال بطل الرواية وإيقاعات الحدث الروائي. امتازت الرواية بكثرة حضور نسقي الاستفهام والأمر، فجاءت الأحداث مبنية على شعرية تساؤلي درامي مشحون بالخوف والرعب مع أوامر حقيقية لذلك الحدث. تجسدت احداث الرواية بصور تشبيهية واستعارية لنقل صورة الحدث الروائي وتجسيد تلك الصور والاحداث المروعة بمختلف الصور لبيان صورة الواقع المرعب.. المصادر والمراجع

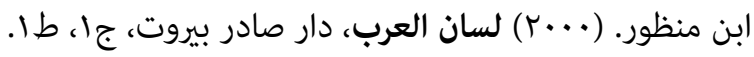

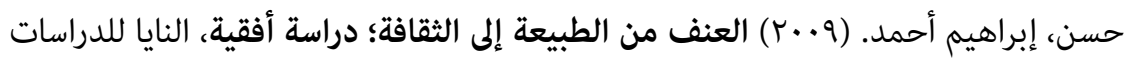
و النشر والتوزيع، الطبعة الأولى، دمشق، سوريا. حسن، مها. (ع...r) الزمن في الرواية العربية، المؤسسة العربية للدراسات والنشر، بيروت، حياوي، محمد. (10 • ( ) رواية خان الشابندر، دار الآداب، طا، بيروت، لبنان.

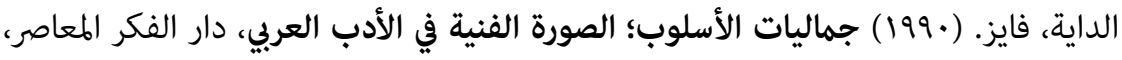

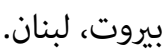
زحاف، آمال. (17(ب) تجليات العنف في رواية سيدة المقام لواسيني الأعرج؛ دراسة

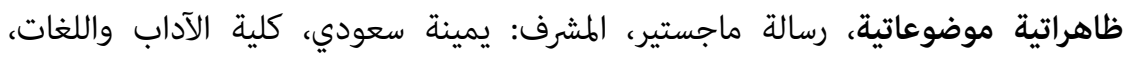
جامعة العربي بن مهيدي، الجزائر. لا مؤلف. (1917) في نقد النثر وأساليبه، ترجمة: عصام الخطيب وتوفيق عزيز، دار الشؤون،

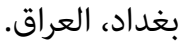
عبود، سلام. (r.r) ثقافة العنف في العراق، منشورات الجمل، ط ا. 
عطية، أحمد محمود. (•999) الرواية السياسية؛ دراسة نقدية في الرواية السياسية العربية، مكتبة مدبولي، القاهرة، مؤسسة مطابع معتوق.

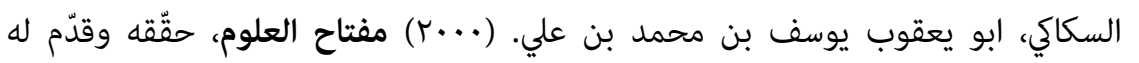
وفهرسه د. عبدالحميد هنداوي طا، دار المكتبة العلمية، بيروت.

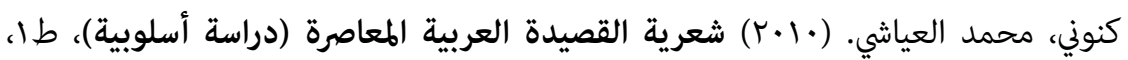

$$
\text { عالم الكتب الحديث، الأردن. }
$$

محمد، كريمة نوماس. (YV (Y) في أسلوبية النثر العربي، دار الكتب، ناشرون التربية، طا.

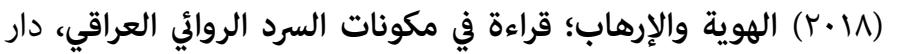

$$
\text { الفرات، العراق. }
$$

مصطفى، رشاد كمال. (10 · أسلوبية السرد العربي (مقاربة أسلوبية في رواية الشحاذ)

$$
\text { نجيب محفوظ، طا، دار الزمان، دمشق، سوريا. }
$$

اليمني، يحيى بن حمزة بن العلوي. (T/191) الطراز المتضمن لأسرار البلاغة وعلوم حقائق

$$
\text { الإعجاز، مطبعة المقتطف، مصر. }
$$

- Brazeal, Gregory Peter (August 2020), The hero \& the victim: Narratives of criminality in Iraq war fiction, PHD Dissertation, Faculty of the Graduate School, Cornell University, New York, united states. 


\section{References}

- Ibn Manzur, (2000), Lisan al-Arab, Dar Sader Beirut, Part 1, ed1.

- Hassan, Ibrahim Ahmed, (2009), Violence from nature to culture; Horizontal Study, Naya Studies, Publishing and Distribution, First Edition, Damascus, Syria.

- Hassan, Maha, (2004), Time in the Arabic Novel, Arab Foundation for Studies and Publishing, Beirut, Lebanon.

- Hayawi, Muhammad, (2015), the novel of Khan Al-Shabandar, Dar AlAdab, 1st Edition, Beirut, Lebanon.

- Daye, Fayez, (1990), Aesthetics of Style; Artistic Image in Arab Literature, House of Contemporary Thought, Beirut, Lebanon.

- Zahaf, Amal, (2016), The manifestations of violence in the novel of Our Lady of Maqam by Wassini Al-Araj; Phenomenological Topical Study, Master's Thesis, Supervisor: Yamina Saudi, Faculty of Letters and Languages, Al-Arabi Bin Mahidi University, Algeria.

- Unknown, (1986) On the Critique of Prose and Its Methods, translated by: Essam Al-Khatib and Tawfiq Aziz, Dar Al-Ash`a`, Baghdad, Iraq.

- Attia, Ahmed Mahmoud (1990), The Political Novel, a Critical Study of the Arab Political Fiction, Madbouly Library, Cairo, Maatouk Press Corporation.

- Kanuni, Muhammad al-Ayashi (2010), The Poetry of the Contemporary Arab Poem (A Stylistic Study), 1st Edition, Modern Book World, Jordan.

- Abboud, Peace, (2002), The Culture of Violence in Iraq, Al-Jamal Publications, Volume 1.

- Al-Sakaky, Abu Ya`qub Yusuf Bin Muhammad Bin Ali, (2000), Miftah Al-Uloom, which was investigated and presented to him and indexed by Dr. Abdul Hamid Hindawi, 1st floor, The Scientific Library House, Beirut.

- Karima Nomas Mohamed, (2018), Identity and Terrorism; Reading in the possibilities of Iraqi novelist narration, Dar Al-Furat, Iraq.

- Muhammad, Karima Nomas, (2017), In the Stylistics of Arab Prose, Dar Al-Kutub, Education Publishers, Edition 1. 
- Mustafa, Rashad Kamal, (2015), The Stylistic Arab Narration (A Stylistic Approach in the Narration of the Beggar) Naguib Mahfouz, Dar Al-Zaman, Damascus, Syria, ed1.

- Brazeal ،Gregory Peter (August 2020)،The hero \& the victim: Narratives of criminality in Iraq war fiction, PHD Dissertation, Faculty of the Graduate School ،Cornell University, New York, united states. 


\section{مطالعات روايت شناسـ عربى}

شايا جايى: · RYVG-VVF

\section{سبك شناسى روايت يردازى و خشونت در رمان عراقى معاصر؛ بر رسى موردى رمان خان الشابندر}

kareema.n@uokerbala.edu.iq

رايانامه: كريمه نوماس محمد المدنى

استاديار كروه زبان وادبيات عربى، دانشگاه كربلا، عراق.

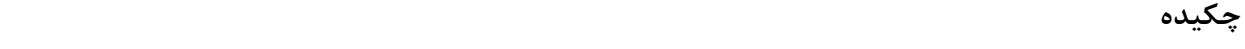
اهميت اين يروهش در سؤال ازكيفيت بررسى ويزّى هاى سبك شناسى در متن روايى عراق نهفته است. باراتراف هاى

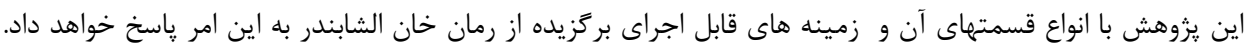

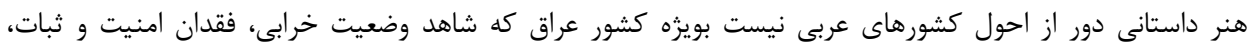

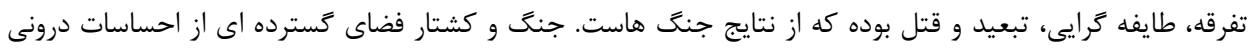

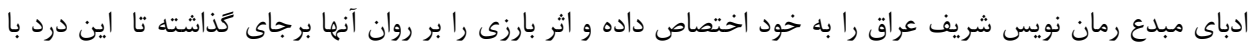

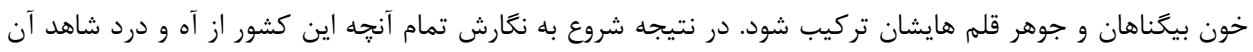

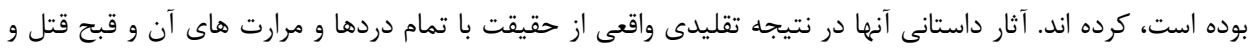

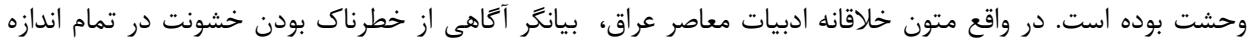

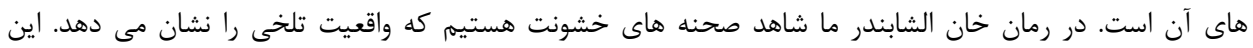

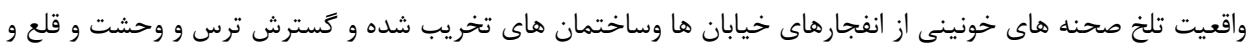

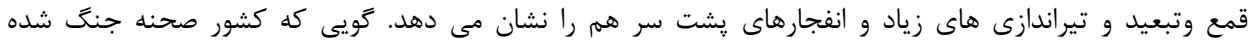

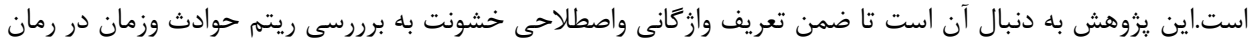

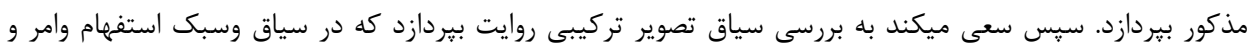

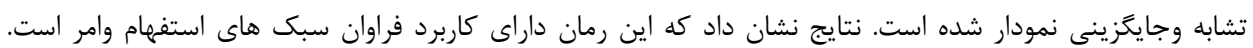

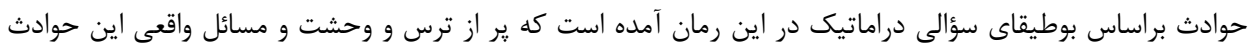

$$
\text { كليد وازهها: روايت يردازى عراقى، صحنه هاى خشونت، رمان عربى معاصر، سبك شناسى روايى. }
$$

استناد: المدنى، كريمه نوماس محمد. بهار و تابستان (99 (1). سبك شناسى روايـت يـردازى و خشـونت در رمـان

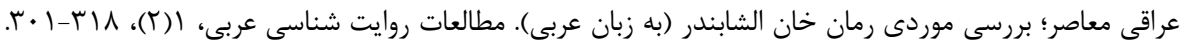

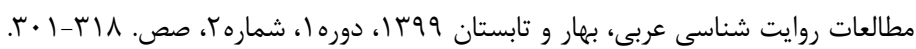

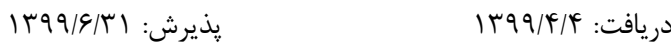

$$
\begin{aligned}
& \text { (C) دانشكده ادبيات و علوم انسانى دانشعاه خوارزمى و انجمن ايرانى زبان و ادبيات عربى ليى }
\end{aligned}
$$

